\title{
User Research of Elderly People Entertainment Product Design Based on the Kano Model and QFD Theory
}

\author{
Fangyu $\mathrm{Li}^{1, \mathrm{a}}$, Wenrui $\mathrm{Li}^{2, \mathrm{~b}}$, Yefei $\mathrm{Li}^{3, \mathrm{c}}$, Mingquan $\mathrm{Shi}^{4, \mathrm{~d}}$ \\ ${ }^{1}$ Southwest Jiaotong University, Chengdu, Sichuan 611756, China \\ ${ }^{2}$ Anhui University, Hefei, Anhui 611756, China \\ ${ }^{3}$ School of Mechatronics Engineering, University of Electronic Science and Technology of China, \\ Chengdu, 611731, China; \\ ${ }^{4}$ Chongqing Institute of Green and intelligent Technology, Chinese Academy of Sciences, \\ Chongqing 400714, China. \\ arosebush2009@126.com
}

Keywords: the Elderly, Entertainment products, Interaction design, Kano model, QFD

\begin{abstract}
This paper put forward a product design method to accommodate game entertainment requirements of the elderly people based on Kano model and Quality Function Deployment (QFD). This method summarize the charm of product attributes, which includes one variable and essential attributes, then determine implements of these attributes according to the function of quality house of attributes weight analysis. The qualitative requirements were obtained from a functional morphology and function of the quality of the interaction and other needs for elderly people entertainment products. A systematic interactive design scheme based on this method is suitable for elderly people with entertainment elements.
\end{abstract}

\section{Introduction}

According to the 2012 Chinese national work conference, there are 185 million people older than 60 years by the end of 2011. It is estimated that the elderly people will exceed 400 million by the end of 2033. These data indicate the grim situation of population aging in our country. More product need to provide by these old people. Cagan pointed out that aging provided a great chance of product which accommodate for these fifty to one hundred years old people in the $21^{\text {st }}$ century [1]. We need to explore and the focus areas.

With the rapid development of Internet, new media and information technology, entertainment products is indispensable to their life partner "Elderly people have a good support in daily" is urgent practical significance with the progress of science and technology [2].Now days most of the elderly people, they are watching TV and playing games and other entertainment in their daily life, and entertainment is the most important way to get outside information for them. However, some of elderly people suffer from "technology phobia" because that the entertainment products are hard to operated and seem complicated to them. They are worry about incorrect operation, low operation efficiency, and fear of wrong operation causing damage. So it is important to study the demand of the elderly user groups with human factors.. The user research on such demands will let entertainment products meet the needs of the elderly with friendly interaction, thus will enrich the cultural life of the old man in their following years.

\section{Demand of Entertainment Products}

\subsection{The function demand}

In the "experience economy" [3], spiritual needs and emotional needs are dominated instead of material needs in the period of todays' rapid development of science and technology and productivity. 
Figure 1 showed the SET factors analysis and the requirements of game entertainment product for elderly combined with Maslow's classic five hierarchy of needs theory.

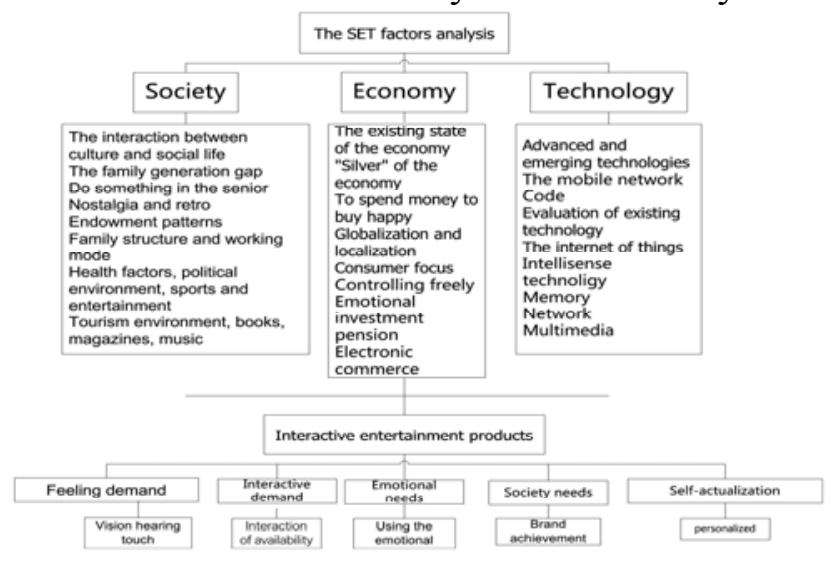

\subsection{Interactive demand}

Fig.1 Factor analysis

Interaction design is different with the traditional product design because the design of product should have good interactive function. It means that users can feel a kind of experience in the process of using product. This experience has a two-way communication between people and products with a "very strong emotion" [4]. The product of the intuitive feelings is the key to determine the success of the product when elderly users using the product. The requirements when Elderly people use entertainment products are a concise and not simple, and operation should also be simple. Thus design is not only derived from the demand but also met the demand [5].

\subsection{Emotional demand}

Designers should not only pay more attention to product's ease of use, but also they emphasize on emotional impact on product [6]. After the beginning of 1970s', designer gradually consider emotional impact except from traditional material aspect. Design objective is to aim to let the life of people become more beautiful, this objective makes emotion and design as unseparated factors in design process. In the progress of entertainment product design for the elderly, the emotional communication requirements should be the basis of design, and let the elderly experience emotions and interest when using the product.

\section{User Research of Elderly People Entertainment Product Design Based on the Kano Model and QFD Theory}

\subsection{Kano model}

Traditional design cognition is single-dimension, which means it is not from the existence of product features in a comprehensive view. The ideas of the Kano model breakthrough single-dimension model, product quality characteristics was put forward to establish a connection between the objectivity of the product and the subjectivity of users, The properties of the products by using the Kano model analysis were shown in figure 2, and it was applied in the old game entertainment products. 


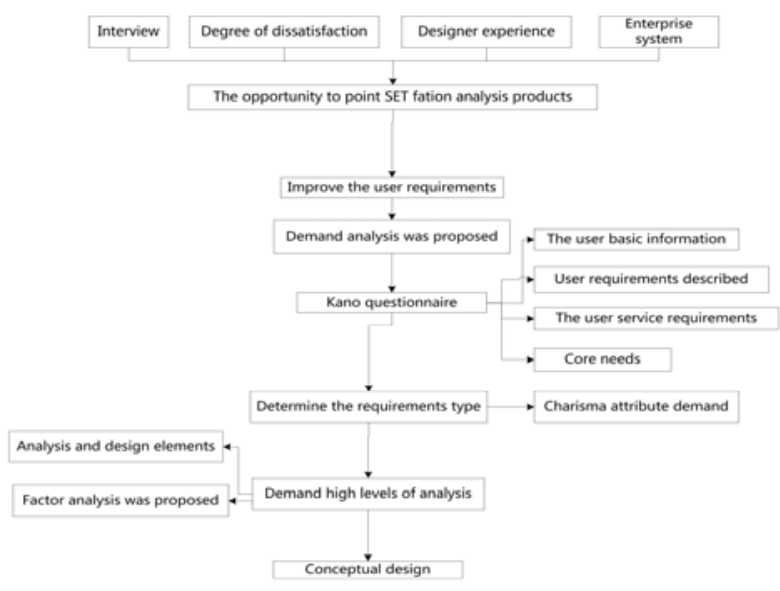

\subsection{QFD theory}

Fig.2 Kano model design elements frame

QFD's aim is to determine the customer, to decide what is customer want, and to consider how to meet the needs of customers. This study applies QFD analysis in the product design, indicate the weight of user needs, set up quality house of entertainment products for elderly people. Figure 3 shown the requirements of the implementation for elderly entertainment design.

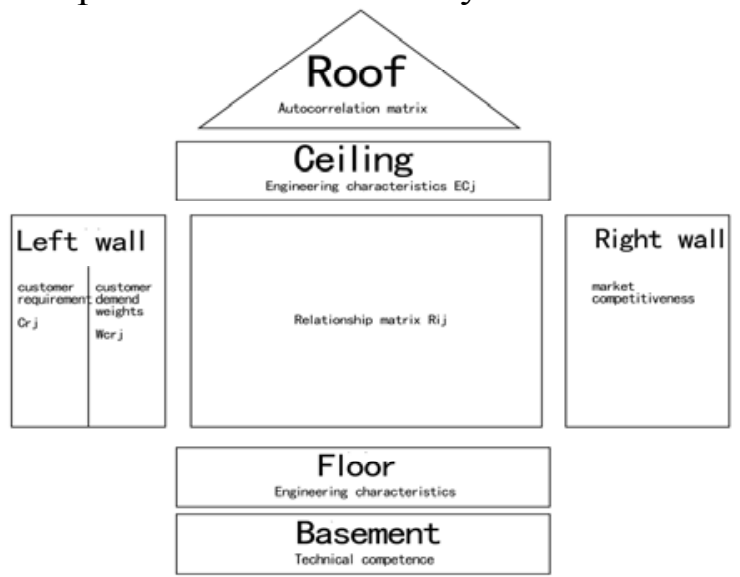

Fig.3 House of quality

\subsection{Sensitive matrix analysis}

The Kano indexes was set into the sensitive matrix with satisfactory degree of influence as abscissa and with dissatisfaction the vertical axis. Observing each index that each indicator has a unique sensitivity. Figure 4 shown that the nearest index with far point has the small sensitivity, conversely, the sensitivity is large.

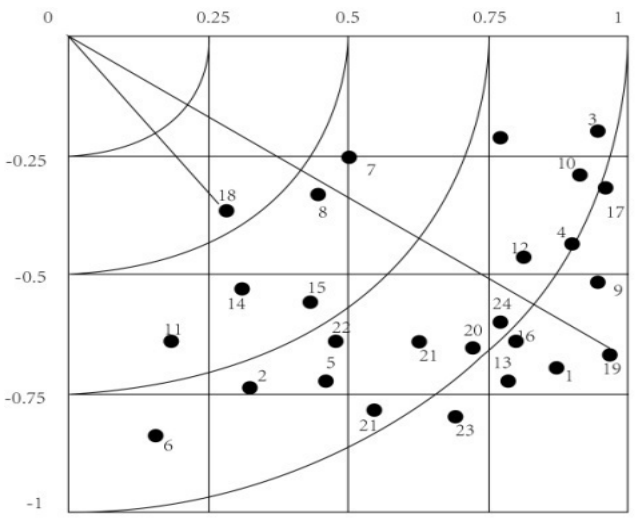

Fig.4 Sensitive matrix

For example, when designing lights in entertainment product function for elderly people, the $18^{\text {th }}$ "light validation"; the $8^{\text {th }}$ "concise" icon near the far point in the matrix, the; $19^{\text {th }}$ "less information" comment function; the 13rd "browse footprint" from far away. This sensitive matrix helps to determine the properties of entertainment and functional attributes. 


\subsection{Implementation evaluation of product}

Charm attribute is still a relatively new concept to the design of the elderly game entertainment products. According to the Kano model analysis of the charm of the property, Analysis of the implementation of the product is shown in figure 5. Design elements are the key parameters that the product developers need to design. It is reliable, effective and quantifiable technology solutions. The charisma attribute should be technical assessed one by one by looking for information.
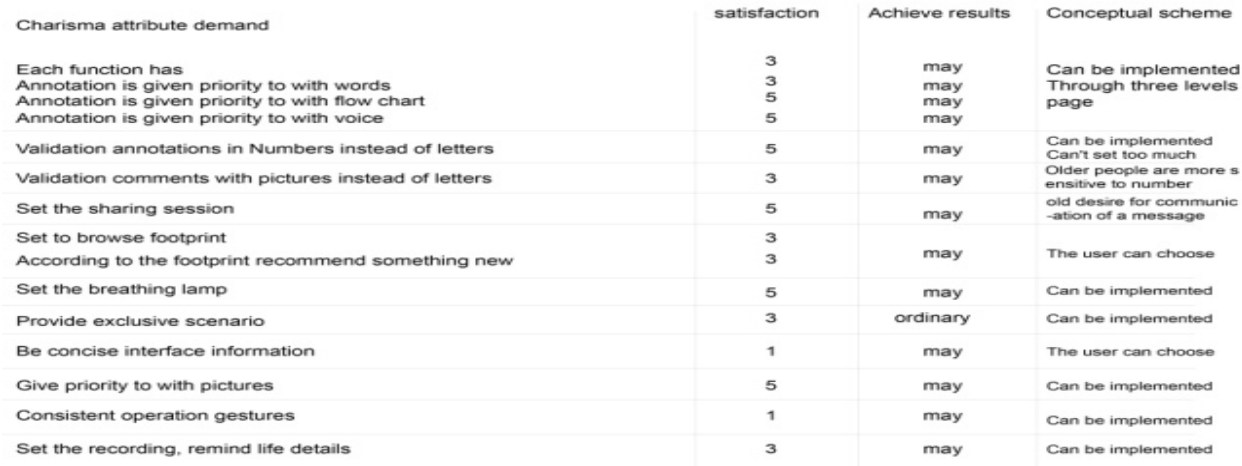

Fig.5 The feasibility of implementation of product

\section{Summary}

Design of elderly entertainment product is a detailed and affinity design which focus on the spirit of elderly users and entertainment demand side. Designer should pay attention to multiple demands of entertainment products for the elderly in the design process, by using the Kano model and QFD, Sensitivity matrix of product can be analyzed and got. This can be as the basis for the implementation of the product. This method provides a good solution to dig user demand for the designer efficiently and finish the elderly entertainment products design.

\section{Acknowledgements}

This work was supported by the Fundamental Research Funds for the Central Universities (268SWJTU15WCX05) in Southwest Jiaotong University, China, the Research Funds for Industrial Design Research Center of Xihua University of Humanities and social science research base in Sichuan Provincial Education Department (GY-13YB-20), the Research Funds for Sichuan Modern Design and Culture Research Center (2014), and the Research Funds for Chongqing Key Laboratory of Automatic Reasoning and Cognition (CARC2014003).

\section{References}

[1] Jonatha Cagan, Craig M. Vogel. Creating Breakthrough Products: Innovation from Planning Program Approval [M] .FT Press. 2001.

[2] E $\bullet H \cdot G o m b r i c h$. A sense of order- Psychological research Decorative Art [M]. Hunan Science and Technology Press.2009.

[3] 2008.B.Joseph Pine II, James H.Gilmore. Experience Economy [M].Beijing. Beijing Machinery Industry Press, 2008.

[4] WANG Yu-shan, LI Shi-guo. The Value and Using of Emotional Memory in the Interactive Design [J]. Packing Engineering, 2011, 32 (2) : 56-59.

[5] SONG Wei-zu The Truth of the Design [M]. Beijing: Beijing Publishing House, 2012.

[6] Donald.A. Norman. Emotional Design [M]. Beijing: Electronic Industry Press, 2005. 